\title{
O DESENVOLVIMENTO DO MARKETING E SUA APROXIMAÇÃO COM OS PARADIGMAS DA CIÊNCIA DA INFORMAÇÃO
}

THE DEVELOPMENT IN MARKETING AND ITS CONVERGENCE TOWARDS

THE PARADIGMS OF INFORMATION SCIENCE

EL DESARROLLO DEL MARKETING Y SU PROXIMIDAD CON LOS

PARADIGMAS DE LA CIENCIA DE LA INFORMACIÓN

${ }^{1}$ Jovenilda Freitas dos Santos

${ }^{2}$ Nídia Maria Lienert Lubisco

Universidade Federal de Sergipe ${ }^{1}$

Universidade Federal da Bahia ${ }^{2}$

\section{Correspondência}

Jovenilda Freitas dos Santos

Universidade Federal de Sergipe

Aracajú - SE - Brasil

Email: jove.ufs@gmail.com

ORCID: http://orcid.org/0000-0002-3744-8699

Submetido em: 10/08/2017

Aceito em: 02/12/2017

Publicado em: 19/01/2018

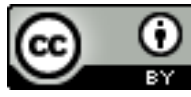

JITA: FB. Marketing 
RESUM0: Pesquisa descritiva que objetiva discutir, sob uma perspectiva histórica, o desenvolvimento do Marketing e sua convergência com os paradigmas da Ciência da informação, conhecidos como paradigma físico, cognitivo e social. Sob o paradigma físico, pontua-se a relação do nascimento de ambas as áreas do conhecimento, que exclui o papel ativo do sujeito cognoscente de todo processo informativo e comunicativo. Em seguida, sob a visão cognitiva, analisa-se a proximidade das áreas, a partir das interações e necessidades do usuário em relação aos sistemas de informação, onde ambas as áreas não tinham como compreender o usuário, de modo a ajustar os serviços a ele. O último estágio do Marketing assemelha-se ao último paradigma da Ciência da informação, cujo objetivo é integrar a abordagem física e cognitiva, considerando a constituição social do indivíduo para construir um modelo ideal que beneficie a todos os envolvidos no processo. Trata-se do paradigma social preconizado por Shera. Conclui-se o estudo, baseado em pesquisa bibliográfica, destacando a sintonia entre o Marketing e a Ciência da informação, a qual beneficia não só teoricamente ambas as áreas, mas também as práticas da Administração e da Biblioteconomia, a partir de um objetivo comum a esses dois campos do saber: a informação e a satisfação dos usuários/clientes, em suas demandas e necessidades informacionais.

PALAVRAS-ChAVE: Marketing. Ciência da informação. Paradigma científico.

ABSTRACT: This research is descriptive and discusses the development of Marketing from a historical perspective and its convergence with the paradigms of Information Science, known as physical, cognitive and social paradigms. Firstly, within the physical paradigm, the birth of both areas of knowledge is related, which excludes the active role of the cognizance subject in all the informative and communicative process. From a cognitive view, the proximity of the areas is analyzed, from interactions and the user's necessity of information systems, where both the systems were not concerned with understanding the user in order to adjust the service to him. The last stage of marketing resembles that of the last paradigm of Information Science, whose objective is to integrate the physical and cognitive approach, considering the social make-up of the individual to construct an ideal model which benefits all those involved in the process. It is the social paradigm advocated by Shera. The study concludes by highlighting the harmony between Marketing and Information Science from which both areas benefit not only theoretically, but it also benefits the theories and practices of Administration and Library Science, from the common objectives to those fields of knowledge: the fulfillment of the informational necessities of the users/clients.

KEYWORDS: Marketing. Information science. Scientífic paradigm.

RESUMEN: Presentamos una investigación descriptiva, cuyo objetivo es discutir, desde una perspectiva histórica, el desarrollo del Marketing y su convergencia hacia los paradigmas de la Ciencia de la Información, conocidos por paradigma físico, cognitivo y social. Bajo el paradigma físico, se muestra la relación del nacimiento de ambas áreas del conocimiento, que excluye el rol activo del sujeto cognocente de todo proceso informativo y comunicativo. Luego, bajo la visión cognitiva, se analiza la proximidad de las dos áreas, a partir de las interacciones y necesidades de los usuarios en relación a los sistemas de información, donde ambas áreas no tenían manera de comprender al usuario y, así, adecuarle los servicios. La última etapa del Marketing es semejante al último paradigma de la Ciencia de la Información, cuyo objetivo es integrar el enfoque físico y cognitivo, teniendo en cuenta la constitución social del individuo para construir un modelo ideal que beneficie a todos los involucrados en el proceso. Se trata del paradigma social según Shera. Se concluye este estudio, basado en una investigación bibliográfica, poniendo de relieve la sintonía entre el Marketing y la Ciencia de la Información, la cual beneficia no solo teóricamente a las dos áreas, sino a las teorías y prácticas de la Administración y de la Biblioteconomía, a partir de un objetivo común a dichos campos del saber: la satisfacción de las necesidades de información de los usuarios/clientes.

PALABRAS ClAVE: Marketing. Ciencias de la Información. Paradigma científico. 


\section{INTRODUÇÃ̃o}

Decorrente da conjuntura econômica e do desenvolvimento do comércio, o Marketing evoluiu e destaca-se como prática e área do conhecimento. Embora originado da Economia, também passou a adotar conceitos de diversos campos da ciência, a exemplo da Estatística, da Psicologia e da Sociologia. Marketing é uma palavra inglesa, cujo significado é mercado em movimento ou em ação. Kotler (1978, p. 38) define mercado como "[...] um grupo distinto de pessoas e/ou organizações que têm recursos que querem trocar ou que poderão concebivelmente trocar por benefícios distintos".

Registros do século XVII, segundo Moreira (2006), atestam que um comerciante estabelecido na cidade de Edo, atual Tóquio, já fabricava produtos específicos com base nas necessidades dos clientes. Contudo, o autor ressalta que, historicamente, o termo marketing teve seu reconhecimento entre 1906 e 1911, em cursos de business, e a American Society, criada em 1930, foi a sua primeira entidade de classe.

De acordo com Andreasen (1987), ao longo da história do crescimento do setor lucrativo, desde o início do século XX, o marketing, como ferramenta de administração, transitou da orientação interna de venda até a produção; só a partir da década de 1950, quando categorizado como marketing moderno, passou a ter uma visão externa. Assim, para compreender a evolução e o contexto no qual ele surge de modo abrangente, sua história pode ser dividida e analisada sob três fases distintas: Era da Produção, Era das Vendas e Era do Marketing propriamente dita.

A partir de então, nesta pesquisa descritiva baseada na literatura especializada, analisase o desenvolvimento do marketing sob uma perspectiva histórica e sua convergência com os paradigmas da Ciência da informação, conhecidos como Paradigma Físico, Cognitivo e Social, tendo em vista que o caráter interdisciplinar da Ciência da informação legitima essa interação, reforçando os dois campos de estudo, quando estabelece cooperação e evidencia as particularidades e diferenças de cada uma.

A matéria, além desta introdução, está apresentada em quatro seções, relativas à Era da Produção, da Venda e do Marketing propriamente dito, sempre de forma associada aos paradigmas da Ciência da informação; está finalizada com considerações finais sobre os benefícios teórico-práticos para ambas as áreas - e também para as disciplinas a elas associadas, Administração e da Biblioteconomia -, a partir do objetivo comum às duas: estudo do fenômeno informação e da satisfação dos usuários/clientes, em suas demandas e necessidades informacionais. 


\section{MARKeting oRIENTAdo PARA A PRodução X PARAdigma físıco}

O advento da Revolução Industrial favoreceu as transformações sociais que se caracterizaram pela passagem da sociedade rural para a urbana, provocando uma verdadeira explosão demográfica nas grandes cidades. O trabalho artesanal e manufaturado deu lugar à fabricação em série, contribuindo para o aumento da produção a um menor custo. Essa mudança afetou profundamente as relações entre a economia e a sociedade, ao deixar de ser orientada pelo controle social, para ser regida por leis de mercado, conferindo às atividades econômicas uma autonomia antes inimaginável. (SANTOS et al., 2009)

Essa fase da história para o marketing ficou conhecida como Era da Produção, caracterizada pela prevalência das leis de mercado, que predominou até os anos de 1920, sendo regida pelo marketing de massa, cuja principal marca era a demanda maior que a oferta. Como tudo que se produzia era vendido, as organizações passaram a exercer certo poder absoluto sobre como fazer e sobre o que disponibilizar para o mercado.

O marketing de massa, ou indiferenciado, enfatiza Matthews (1983, p. 87), “[...] encontra-se calçado no pressuposto de que todas as pessoas possuem necessidades idênticas ou similares, sendo importante concentrarem-se naquilo que é comum a todas e não no que é diferente." $\mathrm{O}$ argumento coincide com a atitude da organização quando procura atender a todos do mesmo modo, ignorando a individualidade do sujeito, cujas necessidades e expectativas são as mais diversas. Segundo Kotler e Lee (2008, p. 37-38): "O problema com esse enfoque é que os administradores de programas e de serviços geralmente se apegam demasiadamente a seus produtos, negligenciando o projeto e a ampliação de seus esforços com base nos desejos e necessidades do cliente." Henry Ford chegou a afirmar que o cliente podia escolher o carro na cor que quisesse, contanto que fosse preto! Percebe-se como a opinião do cliente era desconsiderada, visto as organizações acreditarem ter competência para decidir por ele.

Nessa conjuntura, o marketing centra em planejar produtos mais baratos, com elevado número de características inovadoras, presumindo que esses benefícios fariam com que a organização conquistasse uma fatia maior do mercado consumidor.

Assim, o marketing era percebido essencialmente como um consultor de melhores "armadilhas". Em analogia com a biblioteca e segundo o ponto de vista de alguns gestores, isso pode significar projetar melhores sistemas de informação, maior rapidez no atendimento, ambiente acolhedor, facilidade de estacionamento, dentre outros benefícios correlatos.

Em alusão à epistemologia da Ciência da informação, seguindo a lógica de Capurro (2003), este primeiro momento da evolução do marketing pode ser associado ao nascimento da referida Cência, apoiada pelo paradigma físico e focada no sistema de informação, cuja

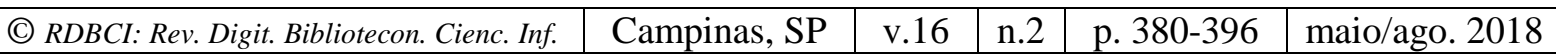


fase excluía o papel ativo do sujeito cognoscente de todo processo informativo e comunicativo. Para Capurro, trata-se da teoria da recuperação da informação, cujo desafio era gerenciar uma grande massa de informação, estreitamente relacionada com a teoria Matemática da Informação, de Claude Shannon, e a da Cibernética, de Norbert Wiener.

\footnotetext{
Mesmo que o usuário fosse perguntado sobre o seu grau de satisfação, certamente era com relação aos serviços prestados (pelo sistema), ou à qualidade das fontes de informação (acervo, ou outro aspecto que fatalmente remeteria à infra-estrutura da unidade de informação. (SO, 2007, p. 170)
}

Nitidamente, o paradigma físico exprime a visão interna e unilateral vivenciada pelo estágio inicial do Marketing e da Ciência da informação, alinhada ao momento histórico, econômico e ao desenvolvimento da teoria vigente à época. Na prática, significa dizer que essa visão ignorava a opinião do usuário por não discutir, nem procurar resolver os seus reais anseios. Logo, supõe-se ser falacioso o discurso de que o usuário não sabe o que quer, inclusive pode funcionar como um escudo para tomar decisões focadas apenas no sistema de informação, comprometendo a imagem da biblioteca por oferecer o que não foi solicitado. Para complementar essa abordagem, recorre-se a Dantas (2006, p. 9), quando diz que, por causa da aparente ignorância do cliente, muitos serviços lhe são "empurrados"; apoiados pela deturpação conceitual de "encantamento", dirigentes tomam decisões e veem o que acontece. Caso os clientes reclamem, provavelmente sua reclamação será ignorada e reforçada pelo "desconhecimento" do cliente quanto às suas próprias necessidades, expectativas e anseios, ou, seja, admitindo implicitamente que os clientes são ignorantes. Se não reclamarem, por omissão, preguiça, desconhecimento ou descrédito na organização, os dirigentes disseminam que "encantaram seus clientes".

Ainda hoje o papel da orientação para produzir vem buscando alcançar alta eficácia na produção e eficiência no baixo custo de distribuição em massa, a exemplo do que ocorre na China e na Índia, quando aproveitam a enorme quantidade de mão-de-obra barata para expandir seu mercado. (KOTLER; KELLER, 2006)

\section{MARKETING ORIENTADO PARA A VENDA X PARADIGMA COGNITIVO}

Teve seu início em 1930 e se caracterizou pelos primeiros sinais de excesso de oferta, decorrente do excesso de produção, quando diversas empresas passaram a utilizar técnicas de venda mais agressivas, procurando vender exclusivamente os produtos acumulados em seus estoques. Kotler e Keller (2006) destacam que tal abordagem ainda é praticada, sobretudo com produtos de baixa procura, sendo interessante vender o que se produz, em detrimento de produzir o que é desejado pelo mercado. Desse ponto, o foco da venda passa a orbitar em torno do cliente, ainda que a oferta seja pré-determinada. $\mathrm{O}$ cliente é visto como quem não está ciente da oferta e que de livre e espontânea vontade normalmente não consumiria produtos e serviços na quantidade desejada pelo vendedor. 


\begin{abstract}
A tarefa do marketing, conseqüentemente, é fazer com que o mercado conheça a oferta que a instituição decidiu tornar disponível e persuadi-lo a aceitá-la. Essa orientação é novamente interna, ela parte da empresa, do que ela deseja oferecer, e encara a tarefa do marketing como uma maneira de superar a indiferença ou preconceito dos consumidores no mercado. (ANDREASEN, 1987, p. 41).
\end{abstract}

Portanto, empreender um esforço agressivo de vendas está plenamente associado à promoção dos produtos e serviços. Conforme Silveira (1992, p. 29): “A orientação para vendas buscava influenciar o mercado, por meio de instrumentos promocionais, visando o aumento de consumo dos produtos existentes". No entanto, não se pode personificar a propaganda e a venda como únicos integrantes importantes do Marketing, porque seria uma contribuição para descaracterizar a compreensão do que ele realmente é.

Em tese, marketing e venda trabalham juntos, mas com objetivos diferentes e que se complementam. O Marketing se preocupa em identificar necessidades e desejos não realizados pelo canal da comunicação, do relacionamento e da confiança. O item vendas investe no poder de persuasão para evidenciar vantagens e benefícios da oferta, que o marketing já trabalhou, convencendo o público-alvo a aceitar ou a comprar o que se deseja. $\mathrm{Na}$ etapa de venda, o marketing não exerce nenhuma influência, pois, no início, já cumpriu a tarefa de despertar o interesse pela oferta, ou de fazer o cliente conhecer a empresa. Ao vendedor competirá persuadir a pessoa a levar o melhor produto ou serviço que o marketing já preparou, pois nem todos tomam a decisão de comprar por vontade própria.

Os administradores, quando orientados para a venda, geralmente veem os consumidores como um entrave ao negócio, isto é, eles consideram que se ao menos tivessem consciência e aprendessem a apreciar "a qualidade e os benefícios" dos produtos que a organização tão bem preparou, certamente suas vendas aumentariam consideravelmente. Sobre o assunto, Drucker (1997, p. 54) adverte: "De fato, este é o problema de muitas organizações orientadas para vendas ou para o produto; elas acham que têm um produto tão bom, que não entendem porque as pessoas não correm para comprá-lo ou usá-lo".

No contexto biblioteca, isso pode ser notado sempre que os seus dirigentes equivocadamente utilizam o marketing para convencer o público de que seu produto vale e merece ser prestigiado. Bibliotecário que não consulta o usuário ilude-se quando julga estar orientado para o marketing, ao pesquisar os melhores canais de publicidade para informar e convencer o público resistente a valorizar seus produtos e serviços. Assim, muitos deles parecem sofrer de "miopia para o negócio", porque mesmo perdendo espaço para outros canais de comunicação, continuam acreditando estar no caminho certo, e que o público é quem enxerga mal, por não perceber e nem saber aproveitar o que tão bem foi preparado para ele.

Essa fase do Marketing assemelha-se com a da Ciência da informação em relação ao Paradigma Cognitivo, ao associar as interações e necessidades do usuário com os sistemas, sem atentar para as questões sociais vivenciadas pelo indivíduo. $\mathrm{O}$ interesse de ambas as

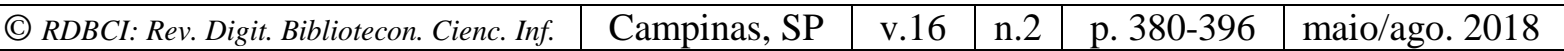


áreas ainda não era compreender o cliente, de modo a ajustar os serviços a ele. Capurro (2003) alerta que a essência cognitiva relega a um segundo plano as estruturas sociais e materiais da existência humana, considerando a informação como algo separado do usuário e se apoia nos processos de informação para saber que transformação eles exercem, ou não, sobre o usuário, entendido como sujeito cognoscente, detentor de modelos mentais.

Na prática, o interesse maior não residia em criar produtos específicos para usuários, mas em compreender como ele pensa, deixando à margem questões das suas práticas sociais. O autor ainda analisa o usuário, buscando a informação a partir de uma necessidade, aliada ao insuficiente conhecimento que ele tem para resolver o seu problema. Nessa perspectiva, o usuário consome o que o bibliotecário escolhe, sendo os canais de distribuição ferramentas imprescindíveis para mediar esse processo, atuando como promoção de suas ofertas. Frohmann, (1995 apud Capurro, 2003) chama o paradigma cognitivo de reducionista, idealista e associal, pois

[...] relega os processos sociais de produção, distribuição, intercâmbio e consumo de informação a um nível numênico, indicado somente por seus efeitos nas representações de geradores de imagens atomizadas. A construção social dos processos informativos, ou seja, a constituição social das necessidades dos usuários, dos arquivos de conhecimentos e dos esquemas de produção, transmissão, distribuição e consumo de imagens, exclui-se, pois, da teoria da biblioteconomia e da ciência da informação.

Ao analisar as causas da estagnação e falência de empresas americanas, Levitt (2007) questionou esse tipo de orientação tradicional, classificando de "miopia em marketing ${ }^{1}$." Para ele, o sucesso da empresa dependia da boa relação com o cliente e não só produzir e vender.

\section{ORIENTAÇÃo PARA O MARKETING X PARAdigma SOCIAL}

Com a orientação para o Marketing propriamente dito, por fim, a sua função começa a ser entendida como uma forma de responder satisfatoriamente às necessidades explícitas e implícitas do consumidor, visando desenvolver produtos para solucionar problemas específicos. (SILVEIRA, 1992). Com base em Amaral (2011), não importa qual seja a organização, mesmo uma biblioteca, quando orientada para o marketing, sua tarefa primordial é determinar necessidades e desejos do seu público-alvo para satisfazê-los com adequado design, boa comunicação, distribuição e preço de oferta competitivamente viável. Então, entendemos que o negócio da biblioteca é disseminar informação representativa, de forma precisa e imparcial, com estratégias focadas em satisfazer ou superar as expectativas dos usuários, considerando as transformações socioculturais, a fim de prestar a correta

\footnotetext{
${ }^{1}$ Miopia em marketing é um artigo de Theodore Levitt, publicado em 1960, pela Harvard Business Review, muito citado no contexto dos perigos causados pela falta de visão da administração, em relação às reais necessidades de mercado. Seu ponto principal está na utilização da imaginação em marketing para enfrentar as consequências autolimitadoras das empresas que buscam ser excelentes de forma convencional em coisas convencionais.
}

\begin{tabular}{|c|c|c|c|c|c|}
\hline (C) RDBCI: Rev. Digit. Bibliotecon. Cienc. Inf. & Campinas, SP & v.16 & n.2 & p. $380-396$ & maio/ago. 2018 \\
\hline
\end{tabular}


assistência para a formação de cidadãos conscientes dos seus direitos e deveres. Assim, a biblioteca é capaz de assegurar a sua evolução e sobrevivência, criando e mantendo um relacionamento saudável com o usuário.

O foco ou filosofia do Marketing voltado para simbiose, produção \& venda, começa a buscar conhecer e atender os anseios do cliente, mudança esta determinante no redimensionamento quanto ao entendimento sobre a própria função do Marketing. Estudiosos convencionaram chamar esse tipo de abordagem - Era do Marketing - de Conceito de Marketing, considerando que muitos novos conceitos advindos de disciplinas como a Psicologia e a Sociologia foram introduzidos no campo comercial a fim de identificar o comportamento e satisfação do consumidor.

A orientação para o marketing foi marcada pela necessidade das empresas de manter seus negócios em longo prazo e cultivar relações estáveis com seus consumidores. De acordo como Richers (2000), a difusão do marketing, mesmo na Europa, foi relativamente lenta, começando a ser mais aceita após a II Grande Guerra. O conceito decorreu do avanço da industrialização mundial que acirrou a competição entre as empresas na disputa pelos mercados. Com isso, o cliente passou a ter poder de escolha, instigando as empresas a adotar medidas para satisfazê-lo: todos os serviços deveriam ser produzidos a partir da identificação dos seus desejos e necessidades.

As empresas, reconhecendo que a decisão final sobre a compra estava nas mãos dos clientes, passaram a adotar práticas como pesquisa e análise de mercado, adequação dos produtos segundo as características e as necessidades dos clientes, comunicação dos benefícios do produto em veículos de massa, promoção de vendas, expansão e diversificação dos canais de distribuição. (LIMEIRA, 2003, p. 2)

Assim, houve uma radical mudança na estrutura organizacional das empresas que passam a entender o cliente como "a alma do negócio." A Sony, por exemplo, preconizou produtos bem sucedidos, que superaram as expectativas, mas que nunca foram solicitados ou até mesmo imaginados pelos clientes, como walkmans, câmeras de vídeo e CDs. Na verdade, apenas inventou produtos com alta probabilidade de acolhimento, pois satisfariam desejos já existentes, porém nunca expressos.

Assim, o organograma tradicional das empresas passou a ser considerado obsoleto e, por isso, invertido como mostram as pirâmides que seguem na Figura. 1:

Figura 1 - Organograma tradicional X organograma de empresa orientada para o cliente 

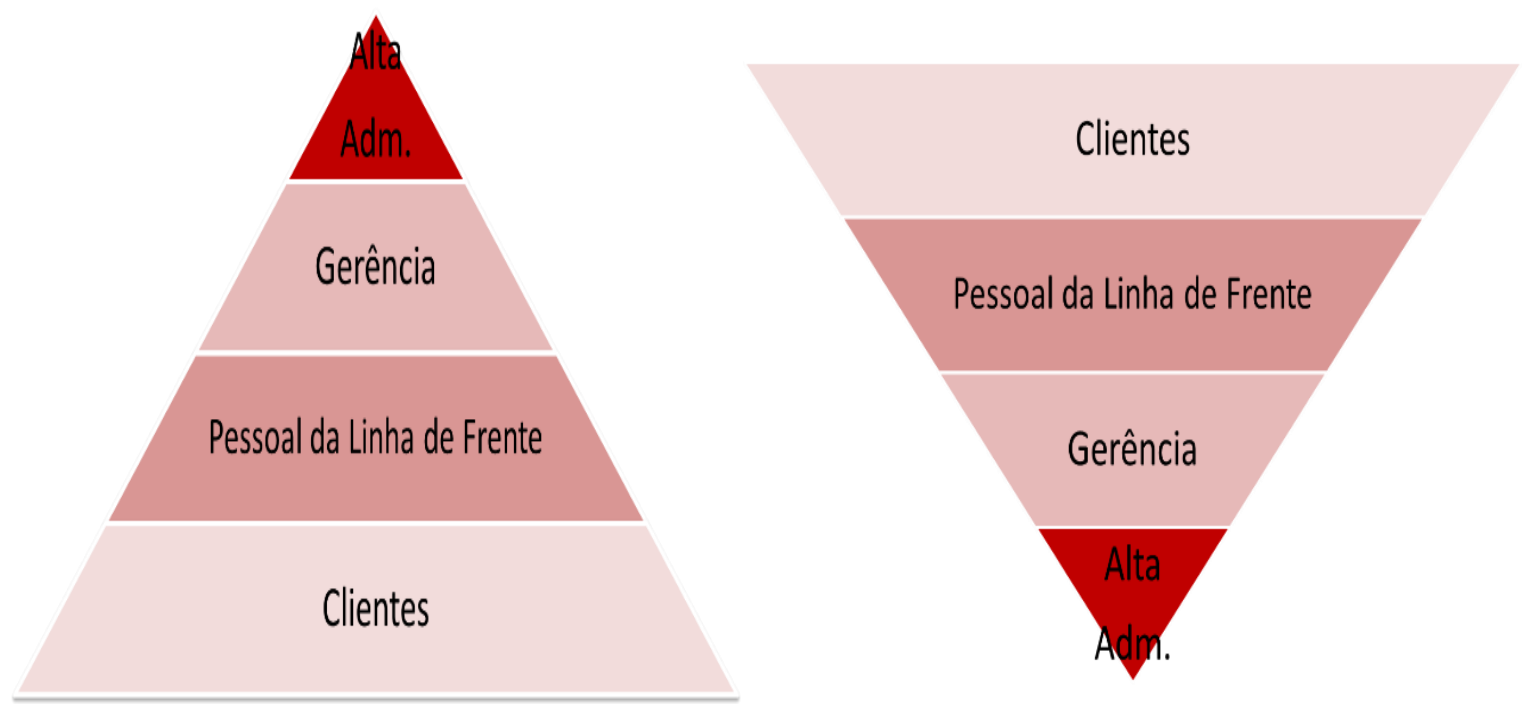

Fonte: Adaptado de Kotler e Keller (2006, p. 139)

A primeira pirâmide mostra a estrutura do organograma convencional onde a alta administração está no topo, representada pela gerência e pelo pessoal da linha de frente; os clientes estão na base. Na nova concepção, atenção ao cliente, vista na segunda pirâmide, os clientes aparecem no topo; em seguida, vem o pessoal da linha de frente, o qual tem contato direto com os clientes; abaixo estão os gerentes, cuja tarefa é apoiar o pessoal da linha frontal, visando ao bom atendimento aos clientes; na base está a alta administração, cuja função é contratar e apoiar os gerentes. (KOTLER; KELLER, 2006). Acrescenta-se que os segmentos mencionados da empresa devem estar todos envolvidos em conhecer e entender os clientes.

Em 1969, Kotler e Levy propuseram a transposição do conceito de marketing às organizações sem fins lucrativos, ao identificar semelhanças entre aquelas com fins lucrativos, após analisarem o desempenho alcançado pelas instituições americanas sem fins lucrativos. No entanto, alguns de seus pares rejeitaram a transposição. O professor Luck publicou artigo no jornal declarando que "[...] marketing deveria limitar-se às atividades que resultam em transações de mercado.” (COBRA, 1997, p. 23) Então, Kotler e Levy reagiram às críticas de Luck, acusando-o de uma nova forma de miopia e, a partir de então, aprofundaram suas ideias acerca do tema. Em 1972, Kotler publica o artigo intitulado $A$ generic concept of marketing, o qual se tornou um clássico por afirmar que o tema também poderia ser aplicado em organizações não ortodoxas. A partir daí, instituições sem fins lucrativos, como entidades religiosas, organizações públicas, partidos políticos e outras, passaram a adaptar suas respectivas realidades às estratégias de marketing.

A ampliação do foco para organizações sem fins lucrativos suscita o surgimento do termo Marketing Social, cunhado por Kotler e Zaltman em 1971 para referir a relação das suas técnicas com a divulgação de uma causa ou comportamento social, para apoiar um

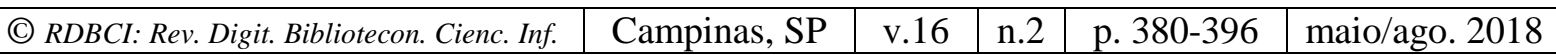


determinado programa social. Conforme Kotler e Keller (2006, p. 719): "As campanhas de marketing social podem ter como objetivo mudar as cognições, os valores, as ações ou os comportamentos das pessoas". Numa biblioteca, as campanhas cognitivas podem explicar a importância da preservação do acervo, já os programas de ação podem ser disseminados para atrair e motivar o público a frequentá-la, e as campanhas de valor ajudam a desconstruir a ideia de que a biblioteca é apenas um local para estudo. Portanto, trata-se de algumas medidas para favorecer a potencialidade da biblioteca de alcançar novos públicos.

Por volta dos anos 1990, o avanço tecnológico favoreceu a gestão em rede de relacionamento com os clientes, ao implementar com mais efetividade as estratégias e programas de marketing, graças ao surgimento dos sistemas de gerenciamento de bancos de dados. A internet e o comércio eletrônico emergem como um novo canal de comunicação, gerando uma revolução na logística do acesso, na disseminação e no uso da informação. Contudo, além da confusão terminológica, Amaral (2011, p. 95-96) observa que,

[...] os ambientes de informação, depois do surgimento da internet e com a evolução da Web social, enfrentam barreiras para ampliar a oferta de informação com a utilização adequada da potencialidade dos recursos tecnológicos disponíveis.

Tudo isso vem reforçar a ideia inovadora de que a unidade de informação precisa ser vista como empresa inserida no negócio da informação, pois a informação é a matéria-prima para geração de conhecimento e ambos são ativos intangíveis de relevância estratégica na evolução da sociedade.

O Marketing entende a informação como insumo imprescindível para conhecer as preferências dos clientes; e a compreensão das suas técnicas permite cooperar para uma gestão assertiva, assessorando no desenvolvimento de ações, produtos e serviços, potencializando os resultados finais.

Parte-se do princípio que marketing da informação é um processo gerencial capaz de contribuir para garantir o futuro da biblioteca e demais unidades de informação como atividade inovadora e criativa, que envolve o planejamento, execução e controle da concepção, determinação de preço, promoção e distribuição de ideias, produtos e serviços de informação. Essa troca com os usuários não apenas deve satisfazer às suas necessidades atuais, consumidores dos produtos e serviços de informação que são oferecidos. $O$ pensamento recente sobre marketing da informação sugere que a tarefa da biblioteca não seja apenas prover necessidades de informação momentâneas, mas também inovar com a oferta de produtos e serviços de informação capazes de atender os interesses da clientela no futuro. (AMARAL, 2011, p. 96)

Entre tantas inovações, os serviços de atendimento ao consumidor e o Customer Relationship Management (CRM) propiciaram a gestão do relacionamento com os clientes em larga escala, levando inúmeros estudiosos a caracterizar essa época como a de busca constante pela personalização em massa. (SANTOS et al., 2009)

Neste contexto, impossível omitir as redes sociais, inseridas na vida das bibliotecas, especialmente, o Facebook, o Twitter, os blogs, o Instagram e o FLICKR, este "[...] uma das plataformas de armazenamento, disponibilização e partilha de fotografias disponíveis aos 
internautas, no que parece ser uma das tipologias de plataformas e de conteúdos com mais sucesso no contexto da Web 2.0." (LEITÃO, 2010, [p. 1]). A respeito do Flickr, destaca-se, por oportuno, a experiência da Biblioteca de Arte da Fundação Calouste Gulbenkian, em Portugal, cujo resultado buscado e obtido caracterizou-se pelo "[...] aumento significativo do conhecimento e utilização das coleções fotográficas disponibilizadas e atraiu novos públicos." (LEITÃO, 2010, [p.1]). Atualmente, as próprias redes sociais aliam a sua função original de relacionamento pessoal e entre comunidades de interesse às oportunidades de veiculação, venda, sondagem e troca de informações sobre variados produtos, desde os industrializados até os artesanais, prática corroborada por técnicas de localizar clientes usando buscadores como o Google.

Outra tendência identificada foi a prática do marketing social, por vezes transformado em vantagem competitiva ao auxiliar o cliente, oferecendo-lhe um "algo mais" no ato da decisão da compra, com base na responsabilidade social e na preocupação com o bem comum.

Este último estágio do Marketing tem como alvo a valorização mútua das relações permanentes com os concorrentes, os canais e os clientes, assemelhando-se ao o terceiro e último paradigma da Ciência da informação, cujo objetivo é integrar a abordagem física e cognitiva com a constituição social do indivíduo, para construir um modelo ideal que beneficie a todos os envolvidos no processo. Trata-se do Paradigma Social, preconizado por Jesse Shera, na década de 1970.

Sob a luz do paradigma social, a necessidade da comunidade é que tem de determinar quais serviços o bibliotecário deverá oferecer para o público. Por conseguinte, um dado registrado num sistema de informação deve ser fruto do conhecimento e do interesse prévio do usuário, por meio de sua participação ativa, entrelaçada no tecido social que o sustenta. "Tal atividade procede não só de sua consciência ou de seus modelos mentais, mas seus conhecimentos e interesses prévios". (CAPURRO, 2003, p. 10). Endossa Matheus (2005, p. 159) que "[...] a abordagem social estudaria o usuário e suas interações com os sistemas, bem como diferentes grupos e contextos sociais, dentro de organizações ou comunidades”.

Mesmo sendo tênue a linha entre os estágios associados à evolução do Marketing com o da Ciência da informação, são visíveis as mudanças de atitude, em que a responsabilidade social e o compromisso coletivo passam a ser discutidos com maior ênfase. Moreira (2006) sinaliza que podemos estar vivendo um quarto momento, cuja ênfase repousa na sociedade e não mais no cliente.

O conceito de marketing evoluiu desde seu surgimento. A redefinição e a ampliação teórico-operacional são consequências da própria evolução da sociedade, que influencia seus aspectos multiculturais e sociais. A evolução das práticas empresariais, motivada pela dinâmica econômica, social, política e tecnológica mundial, é que faz surgir novos juízos de aplicações. 
Nesse espectro, mencionam-se algumas técnicas mercadológicas que podem ser utilizadas: análise do ambiente, do consumidor, da concorrência; a pesquisa de mercado; a segmentação; e os sistemas de informação de marketing. Em relação aos princípios estreitamente relacionados à abordagem mercadológica estão a inteligência de marketing, a qualidade, o valor agregado e o relacionamento. Ao acompanhar a possibilidade de uso das novas tecnologias, surge o marketing direto, o comércio eletrônico e a ação do marketing no ciberespaço.

Retomando a aproximação do desenvolvimento do campo do Marketing com os paradigmas epistemológicos da Ciência da informação, embora trate de uma abordagem ainda incipiente, considera-se aqui necessária, visando analisar as distorções associadas à prática de marketing em unidades de informação, em virtude das semelhanças analisadas em cada uma das etapas das duas disciplinas. Ambas têm suas teorias divididas em três fases distintas e abrangentes, influenciadas pelas forças socioeconômicas e pelas tecnologias eletrônicas que criam novas necessidades. Seus conceitos são firmados à medida que os paradigmas são revistos, porém, as novas práticas não eliminam as anteriores. Elas muitas vezes se complementam e o que determina a escolha de uma ou de outra - ou de ambas - é o objetivo que se deseja alcançar, ideia reforçada pelo que segue: "Desta forma, é possível entender que as abordagens anteriores continuam sendo essenciais para o estudo dos problemas associados à informação, em virtude dos diferentes aspectos analisados por cada uma”. (MATHEUS, 2005, p. 159)

A seguir, apresenta-se um quadro sintético com fins de ilustrar a contínua evolução da definição do termo marketing, observando o estabelecimento de relação com a própria evolução da sociedade, tendo em vista que o mercado se desenvolve e gera necessidade de conceituá-lo de forma cada vez mais ampla.

Quadro 1 - Evolução da definição de Marketing 


\begin{tabular}{|l|l|l|}
\hline American Marketing Association & 1948 & $\begin{array}{l}\text { Execução das atividades de negócio que encaminham o fluxo de } \\
\text { mercadorias e serviços, partindo dos produtores até os } \\
\text { consumidores finais. }\end{array}$ \\
\hline American Marketing Association & 1960 & $\begin{array}{l}\text { O desempenho das atividades de negócios dirige o fluxo de bens e } \\
\text { serviços do produtor ao consumidor ou utilizador }\end{array}$ \\
\hline Lester Wunderman & 1961 & $\begin{array}{l}\text { Marketing direto é a primeira aplicação a ser aceita; apoia-se na } \\
\text { oferta e divulgação de produtos e serviços por meio do envio de } \\
\text { catálogos impressos pelo correio, e-mail e outros meios de } \\
\text { comunicação. }\end{array}$ \\
\hline Ohio State University & 1965 & $\begin{array}{l}\text { O processo na sociedade pelo qual a estrutura da demanda para } \\
\text { bens econômicos e serviços é antecipada ou abrangida e satisfeita } \\
\text { pela concepção, promoção, troca e distribuição física de bens e } \\
\text { serviços. }\end{array}$ \\
\hline Philip Kotler e Sidney Levy & 1969 & $\begin{array}{l}\text { O conceito de marketing deveria abranger também as instituições } \\
\text { não lucrativas. }\end{array}$ \\
\hline Philip Kotler e Gerald Zaltman & 1971 & $\begin{array}{l}\text { Marketing social caracteriza-se pela criação, implementação e } \\
\text { controle de programas calculados para influenciar a aceitabilidade } \\
\text { das ideias sociais, envolvendo considerações de planejamento de } \\
\text { produto, preço, comunicação, distribuição e pesquisa de } \\
\text { marketing. }\end{array}$ \\
\hline Leonard Berry & 1983 & $\begin{array}{l}\text { Marketing de relacionamento é a tarefa de criar forte lealdade } \\
\text { fidelização) dos consumidores, criando relacionamentos } \\
\text { duradouros e administrando-os para o benefício mútuo. }\end{array}$ \\
\hline
\end{tabular}

Fonte: Elaboração das autoras.

A união dos atores envolvendo o Marketing e a Ciência da informação tende a solucionar problemas comuns relativos a métodos, usos e paradigmas envolvendo as duas disciplinas. Para Bonifácio (2015), após análise de conteúdo a respeito da interdisciplinaridade possível entre ambas as áreas, o uso das técnicas de marketing dentro da Ciência da informação é uma das possíveis abordagens para propostas de técnicas e metodologias mitigadoras desses problemas.

No embasamento utilizado para a elaboração desta pesquisa, é evidente o Marketing atuando em perfeita sintonia com a Ciência da informação. Esse e outros argumentos constatam-se por meio do crescente interesse pelos estudos de Marketing na Ciência da informação, embora a interdisciplinaridade ainda seja pouco trabalhada. Afinal, como afirma Le Coadic (1994, p. 82), 
A ciência da informação tem por objeto o estudo das propriedades gerais da informação (natureza, gênese e efeito), ou seja, mais precisamente: a análise dos processos de construção, comunicação e uso. E a concepção dos produtos e sistemas que permitem sua construção dos produtos, sistemas, comunicação, armazenamento e uso.

Há como idealizar o marketing sem análise dos processos de construção, comunicação e uso da informação? A essa pergunta, conclui-se buscando resposta em dois autores: Kuehl (1973) considerava a utilidade da aplicação do Marketing para o estudo de necessidades de informação dos usuários, ao identificar suas bases comuns à Ciência da informação no que respeita à satisfação de suas necessidades, por meio da realização de troca; e Hewis (1990) afirma que tanto a Ciência da informação quanto o Marketing estão voltados para o mesmo objetivo, ou seja, satisfazer as necessidades dos usuários/clientes.

\section{CONSIDERAÇÕES FINAIS}

A pesquisa mostra os pontos de ligação entre o desenvolvimento do Marketing com os paradigmas da Ciência da informação, revelando que embora exista convergência entre as áreas, muito pouco se discute sobre a importância dessa cooperação interdisciplinar no âmbito da Ciência da informação. Lamentavelmente, quando ocorre, no geral é feita de forma superficial, chegando até a existir resistência quanto ao intercâmbio de suas técnicas, conceitos e métodos, empregados a serviço da Ciência da informação, seja por falta de conhecimento, por resistência ou outras prioridades assumida pelos pesquisadores da área.

Concordamos com Amaral (2011) quando diz que a falta de estudo tem a ver com a recente transposição conceitual de Marketing para o campo da Ciência da Informação, o que pode justificar o baixo quantitativo de pesquisadores dessa área estudando o Marketing.

Conhecer a história e o desenvolvimento do Marketing, buscando aproximá-lo dos paradigmas da Ciência da informação, significa a possibilidade de conhecer e interpretar as definições, transposição de conceitos, teorias, métodos e estratégias do marketing, as quais vêm pouco a pouco vêm sendo estudadas no âmbito da Ciência da informação.

A intenção de aproximar as duas disciplinas visou evitar a superposição de esforços e promover a absorção recíproca de contribuições que ambas aportam, tanto do ponto de vista teórico, quanto da prática na gestão da informação.

A análise das diversas definições sobre marketing, surgidas ao longo do tempo, abre perspectivas para evidenciar sua capacidade de oferecer teorias e modelos à ciência da informação e vice-versa, tendo em vista que ambas têm uma preocupação em comum: a satisfação do usuário e a informação, embora com focos diferentes, mas nem por isso divergentes. Isso porque a essência das duas áreas é a informação e, por conseguinte, buscam responder e atender às inquietações de diversos grupos sociais, ao buscar satisfazer necessidades informacionais, tanto do ponto de vista individual, quanto do coletivo.

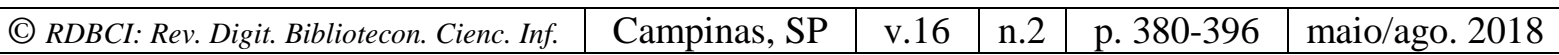


Considerando o caráter interdisciplinar da ciência da informação, quando analisada pelo viés de a informação ser a base do conhecimento, e de o marketing depender de informação para obter o conhecimento acerca do cliente, podemos considerá-lo como fundamental para a ciência da informação.

\section{REFERÊNCIAS}

AMARAL, Sueli Angélica. Marketing da informação: abordagem inovadora para entender o mercado e o negócio da informação Ci. Inf., Brasília, DF, v. 40 n. 1, p.85-98, jan./abr., 2011. Disponível em: < http://revista.ibict.br/ciinf/article/view/1327/1506>. Acesso em: 8 dez. 2017.

ANDREASEN, Alan R. Avanço do marketing para biblioteca do futuro. In: SILVEIRA, Amélia (Org.) Marketing em bibliotecas e serviço de informação: textos selecionados. Brasília: IBICT, 1987. p. 37-64.

BONIFACIO, Everton Lopes. Ciência da informação e marketing: uma interdisciplinaridade possível. Ciência da informação, Brasília, DF, v. 44, n. 3, p. 366-380, set./dez. 2015. Disponível em: <http://revista.ibict.br/ciinf/article/view/1791〉. Acesso em: 10 dez. 2017.

CAPURRO, Rafael. Epistemologia e ciência da informação. In: ENCONTRO NACIONAL DE PESQUISA EM CIÊNCIA DA INFORMAÇÃO, 5., 2003, Belo Horizonte, Anais... Belo Horizonte: Escola de Ciência da informação da UFMG, 2003. p. [1-18]. 1 CD-ROM.

COBRA, Marcos. Marketing básico: uma abordagem brasileira. 4. ed. São Paulo: Atlas, 1997.

DANTAS, Edmundo Brandão. A informação como insumo da prática do marketing na gestão do conhecimento do cliente. Inf. \& Soc.: Est., João Pessoa, v. 16, n. 1, p. 35-47 já./jun. 2006. Disponível em: <http://www.ies.ufpb.br/ojs/index.php/ies/article/view/440/1492>. Acesso em: 10 dez. 2017.

DRUCKER, Peter Ferdinand. Administração de organizações sem fins lucrativos: princípios e práticas. 4. ed. São Paulo: Pioneira, 1997. 166 p.

KOTLER, Philip. Marketing para organizações que não visam o lucro. São Paulo: Atlas. 1978. $430 \mathrm{p}$.

HEWIS, Elizabeth. Information need and use studies. Annual Review of Information Science and Technology (ARIST), v. 25, p. 145-172, 1990.

KOTLER, Philip. Marketing para organizações que não visam o lucro. São Paulo: Atlas. 1978. $430 \mathrm{p}$. 
KOTLER, Philip; KELLER, Kevin Lane. Administração de marketing. 12 ed. São Paulo: Pearson Prentice Hall, 2006. 750 p.

KOTLER, Philip; LEE, Nancy. Marketing no setor público: um guia para um desempenho mais eficaz. Porto Alegre: Bookman, 2008. 350 p.

KUEHL, Philip. G. Marketing viewpoints for user need studies. In: TAYLOR, R. S. (Ed.) Economics of information dissemination: a symposium. Syracuse: Syracuse University: 1973: 49-67 apud Sueli Angélica do Amaral. Marketing: abordagens em unidades de informação. Brasília: Thesaurus, 1998. 245p.

LE COADIC, Yves, F. Ciência da informação. Brasília: Briquet de Lemos Livros, 1994. p. 82.

LEITÃO, Paulo Jorge O. Uma biblioteca nas redes sociais: o caso da Biblioteca de Arte da Fundação Calouste Gulbenkian no FLICKR. In: CONGRESSO NACIONAL DE BIBLIOTECÁRIOS, ARQUIVISTAS E DOCUMENTALISTAS, 10., Guimarães. Actas. Lisboa: BAD, 2010. Disponível em:

<http://www.bad.pt/publicacoes/index.php/congressosbad/article/view/189>. Acesso em: maio 2017.

LEVITT, Theodore. A imaginação de marketing. 2. ed. São Paulo: Atlas, 2007.

LIMEIRA, Tânia Maria Vidigal. Fundamentos de Marketing. In: DIAS, Sérgio Roberto. (Coord.). Gestão de marketing. São Paulo: Saraiva, 2003, cap. 1.

MATHEUS, Renato Fabiano. Rafael Capurro e a filosofia da informação: abordagens, conceitos e metodologias de pesquisa para a Ciência da informação. Perspectiva Ciência da informação, Belo Horizonte, v. 10, n. 2, p. 140-165, jul./dez. 2005.

MOREIRA, Roberto Resende. $O$ uso da reclamação com meio de coleta de informações nas ouvidorias públicas. 2006. 190f. Dissertação (Mestrado em Ciência da informação) Faculdade de Economia, Administração, Contabilidade e Ciência da informação e Documentação (FACED), Universidade de Brasília, Brasília, 2006.

RICHERS, Raimar. Marketing: uma visão brasileira. 3. ed. São Paulo: RCA, 2000.

SANTOS, Tatiani et al. O desenvolvimento do marketing: uma perspectiva histórica. Revista de Gestão USP, São Paulo, v. 16, n. 1, p. 89-102, jan./mar. 2009.

SILVEIRA, Amélia. Marketing em bibliotecas universitárias. Florianópolis: UFSC, 1992. $161 \mathrm{p}$.

SO, Denise Rodrigues. A segmentação de clientes em bibliotecas. 2007. 189 f. Dissertação (Mestrado em Ciência da informação) - Escola de Comunicação e Arte, Universidade de São Paulo (USP), São Paulo. 2007. 

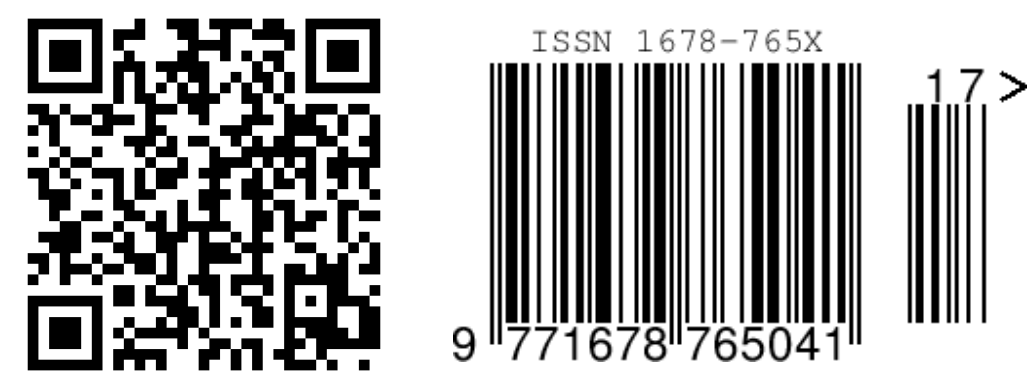